\title{
Dos obras mágicas toledanas del Libro de Raziel alfonsí en siete libros
}

\author{
Two Toledan magic works from Alfonsine Book of Raziel \\ in seven books
}

\author{
Miguel Pérez Rosado \\ miperrosado@gmail.com
}

ORCID iD: https://orcid.org/0000-0003-0356-3258

RESUMEN: Los ff. 1v-2r del ms. 94-22 de la Biblioteca Capitular de Toledo presentan la versión castellana inédita y desconocida de dos obras mágicas del Libro de Raziel alfonsí en siete libros, del que, hasta ahora, se conservan escasos testimonios en castellano.

Palabras clave: Alfonso X, Libro de Raziel, magia, imágenes, Toledo.

ABSTRACT: The ff. 1v-2r of ms. 94-22 from Toledo's Cathedral Library keep an unpublished and unknown Castilian version of two works from Alfonsine Book of Raziel in seven books. This is one of the few Castilian samples that survives today.

Keywords: Alfonso X, Book of Raziel, magic, images, Toledo.

\section{INTRODUCCIÓN}

Con la signatura Ms. 94-22 se guarda en la Biblioteca Capitular de Toledo un códice manuscrito, del que estudiaremos los folios $1 \mathrm{v}-2 \mathrm{r}$.

Describen este libro diversos eruditos desde el siglo XVIII: B. J. Feijoo, Heine o Amador de los Ríos (Martínez, 2016: 95-100). Ya en 1753 se realizaron tres copias de una obra de este códice, por iniciativa de F. J. de Palomares, dos de las cuales mencionaron sus folios 1v-2r. Millás Vallicrosa (1942: 77) describió así nuestro fragmento:

Sigue luego un texto, escrito en castellano, de distinta letra, en papel muy deteriorado, sobre conjuros mágicos y angélicos. Está truncado y es muy ilegible. Léese en el fol. 2 r.: "Estos son los nombres de los angeles de la... 
Carcabel, Netriel, Del?, Yoch, Hyhehu..." Al parecer, esta terminología angelológica es similar a la que aparece en las fórmulas de conjuración y en la magia oriental e islámica.

\section{El LibRo DE RAZIEL ALFONSÍ EN SIETE LIBROS}

El Libro de Raziel se presenta como una recopilación de textos hebreos y latinos, entre los que destacan libros de magia como el Sepher ha-Razim o Libro de los secretos. El Libro de Raziel pretende ser un regalo del ángel Raziel a Adán para compensarlo de la pérdida de conocimientos sufrida al ser expulsado del Paraíso. El libro pasaría a Noé y de él a Salomón.

Aunque esta versión en siete libros está escrita en latín, la primera impresión de un Libro de Raziel, en cinco libros, se hizo en lengua hebrea en Amsterdam, 1701. Su estructura difiere de nuestra versión latina y sugiere una cadena manuscrita de eslabones inciertos.

El Libro de Raziel se conserva en diferentes versiones y en diversos formatos. Aquí nos centraremos en la versión alfonsí en siete libros. Esta versión se transmite en dos manuscritos: el R: ms. Reg. Lat. 1300, Biblioteca Apostolica Vaticana, Città del Vaticano y el H: ms. 14 B 36, Universitäts-und Landesbibliothek, Halle. A ellos podríamos añadir dos fragmentos que conservan, aproximadamente, los libros VI y VII de nuestro Raziel: se trata de M: ms. Clm 51, Bayerische Staatsbibliothek, München, ff.111 ${ }^{\mathrm{r}}-123^{\mathrm{v}}$, y L: ms. Plut.44 cod. 33, Biblioteca Medicea Laurenziana, Firenze (Thorndike, 1947: 254). Estos dos últimos manuscritos fragmentarios transmiten también las obras mágicas que estudiamos en estas páginas.

En el prólogo de esta versión, un tal Iohannes clericus -identificado por algunos con Juan de Aspa - atribuye la composición de esta obra a la iniciativa del rey Alfonso X de Castilla. Más adelante, indica que la tradujo al castellano del latín, creando cierta confusión sobre la lengua del modelo (García Aviles, 1997: 30). Según estos datos, la obra se compondría, en esta forma, en torno a 1259 (D’Agostini, 1992: 39-45). Hasta aquí, la idea tradicional del Libro de Raziel. Una buena exposición de ella puede encontrarse en L. Fernández Fernández (2013: 289-323), que la sitúa en el contexto de la obra científica alfonsí. Otros estudios han puesto en duda su datación y autoría, considerando este Libro de Raziel un grimorio terminado de componer entre 1350 y 1375 . Su autor utilizaría el nombre de Alfonso X para prestigiar su contenido (Gehr, 2012: 184).

El Liber Razielis alfonsí es una obra en siete libros o tratados. El primero, llamado clave, trata de los consejos de Raziel, de planetas y de signos; el segundo, ala, de piedras, hierbas, animales y de las letras hebreas; el tercero, titulado suffumigia, trata de sahumerios; el cuarto, de estrellas, cielos y divisiones del 
tiempo; el quinto, de la purificación del hombre; el sexto, de los ángeles de los siete cielos, y el séptimo y último, de obras ${ }^{1}$, imágenes y de magia.

Dado que las obras mágicas toledanas de estas páginas corresponden al sexto libro de Raziel, recordamos que este fue una ampliación del Sepher ha-Razim. El Sepher es un libro reconstruido a partir de fragmentos hebreos, supuestamente entregados por Raziel a Noé, editado por Mordecai Margalioth en 1966 (Morgan, 1983: 1).

El libro sexto del Raziel comienza recordando la vinculación de Adán, Noé y Salomón con el ángel y su libro. Sigue una descripción de los siete cielos con sus ángeles, divididos en ejércitos o en alturas, y los favores que pueden esperarse de cada uno de ellos. La mayoría de estos favores se logra mediante imágenes u obras, es decir, objetos que consisten en una superficie, generalmente metálica, sobre la que se dibujan o escriben nombres o caracteres. Después pueden sahumarse y, bajo la influencia de un astro, exponerse, conjurando los ángeles de la altura correspondiente. Este libro sexto se titula Liber Samayn en nuestros mss. R y M.

Además de la versión alfonsí en siete libros, conservamos otras variantes como la del ms. 970, Bibliothèque Municipale, Lyon, estudiada por François Secret (1969: 227-228). La copia en inglés del Sloane ms. 3648, British Library, London —añadamos el 3628- quizá transmita una obra confundida con el Raziel: el Liber Salomonis (Laat, 2018). El ms. 3666, Bibliothèque Nationale de France, Paris - Cyfra Rasiel en dos libros - llamó la atención de François Secret (1969: 240) por sus diferencias con las otras versiones, incluida la edición de Amsterdam, 1701. El Cod. mag. 40, Universitätsbibliothek, Leipzig, de hacia 1750, podría relacionarse con el citado por Secret (1969: 239), vagamente descrito como DCCXLV -y como "Leipzig, Biblioteca del Senado, Cod. lat. 745" por Alejandro García Avilés (1997: 28 n.28)—. También destaca la versión italiana de Sloane, ms. 585, British Library, London (Martínez de Carnero, 2002). Lamentablemente, nada sabemos de la versión de Enrique de Villena a la que se refiere Lope de Barrientos, al expurgar su biblioteca (Barrientos 1994: 149-151).

De cierta versión occitana del siglo XV (Giralt, 2014) trataremos más adelante.

\section{LOS TESTIMONIOS CASTELlanOS DEL LIBRO DE RAZIEL}

El fragmento que presentamos supondría el tercer testimonio castellano del Liber Razielis.

\footnotetext{
1 Para este artículo elegimos la palabra obra, basándonos en varios epígrafes del ms. R, f.228-229, que presentan el ablativo opere. De manera más confusa, aparece el término operationes en M, f.117vb. No sería incorrecto el término imágenes, para estos objetos, pese a que no mencionen una representación gráfica convencional, sino meros nombres. Evitamos su sinónimo, talismán, que, según Corominas-Pascual -DCECH-, solo se documenta desde el Diccionario de Autoridades [1726-39].
} 
2.1. El primero -y, probablemente, el más antiguo - lo presentó D’Agostino (1979: 48), siguiendo a Anna María Vaccaro (1959). Corresponde al libro IV de Raziel y se encuentra en el Libro de Astromagia, atribuido a Alfonso X, que cita explícitamente el nombre del ángel. Este fragmento traduce literalmente su original latino.

2.2. El segundo testimonio castellano fue hallado por José Rodríguez Guerrero (Gehr, 2012: 194-195). Se encuentra en los ff.96r-97v del ms. lat. oct. 231, Universitätsbibliothek Johann Christian Senckenberg, Frankfurt. El fragmento se presenta con el título "Ex libro Razielis" y Gehr sitúa su contenido entre los folios 22r-28v del Liber Razielis de Halle. El texto castellano explica la técnica de los sahumerios y corresponde al libro III latino.

2.3. Finalmente, el códice en que se lee nuestro testimonio respondería a la siguiente descripción:

BCT Ms. 94-22:

Códice facticio compuesto por, al menos, dos manuscritos mal foliados: los ff. $45 \mathrm{r}-77 \mathrm{v}$ serían un segundo manuscrito insertado a posteriori en el libro.

S. XIV, península ibérica; probablemente, Toledo.

97 ff. de papel + 2 hojas de pergamino o vitela como cubiertas; 160 x 120 mm.

\section{Contenido:}

f.1r: Tratado latino desconocido.

ff.1v-2r: Fragmentos castellanos acéfalos del Libro de Raziel.

ff.2v-44v: Apuntes de gramática en latín.

ff.45r-77v: Filosophia de Virgilio Hispano.

ff.78r-79v: Sentencias latinas.

ff.80r-90r: Apuntes de gramática en latín, continuación de los ff.2v-44v.

f.90v: Accessus a Boecio, De Consolatione Philosophiae.

ff.91r-92r: Sermón en latín y castellano y sentencias sobre la hierba yssopus. f.92v: Accessus a Esopo.

ff.93r-96r: Diversas sentencias goliárdicas latinas.

ff.96v-97r: Accessus a Pierre de París.

Latín y castellano. Letra gótica cortesana descuidada.

\section{Encuadernación:}

Encuadernación en pergamino con guardas de pergamino o vitela sobre las que se pegan los ff.1r y 97v del texto en papel. En el lomo, la signatura actual y las letras: "Virgil. Philosofia. M.S."

\section{Fortuna del manuscrito:}

Parece proceder del propio entorno catedralicio toledano. El primer folio lleva lo que parece una signatura antigua "Cax 17-4" y, tachada, otra que se identifica a duras penas como "Cax 21-4". 


\section{Otra información:}

El folio 1 aparece pegado a la guarda de vitela, de manera que el texto castellano comienza en el $1 \mathrm{v}$. Sin embargo, puede pensarse que el $1 \mathrm{r}$ de papel - no el actual de vitela - transmite parte de nuestros fragmentos, que podría leerse despegando este folio 1 de las guardas. Por otro lado, dicho folio se encuentra rasgado en su parte superior, impidiendo la lectura de algunas líneas de texto. El librito presenta manos de diferentes copistas. Sin embargo, si aceptamos que los ff.45r-77v pudieron añadirse en una encuadernación posterior, el resto del libro podría estar copiado de una sola mano, con excepción de algunos folios, como el 78 y el 91. Esto podría explicarse como la intervención de algún compañero del estudiante propietario del códice — trataremos esto más adelante- que se describe aquí. El f.78r se encuentra numerado, pero un trazo vertical descuidado, hace pensar que se escribió un 178. De ahí que numerosos estudiosos hayan contado desde este número las hojas del libro por error.

$\mathrm{Su}$ conservación es defectuosa en general, tanto por el estado de algunos folios estropeados de insectos, como por el desprendimiento de otros, como los ff.79-80.

\section{Bibliografia:}

Millás Vallicrosa (1942: 77-78); Pérez López (2007: 129); Faulhaber (2016); Martínez (2016: 95-97).

Época y autor:

Aceptar con D’Agostino (1992: 44) el año de 1259 para la versión castellana del Raziel, sería datar la redacción de nuestro fragmento de una manera muy clara. Teniendo en cuenta las consideraciones de Gehr (2012: 184), a pesar de algún aspecto oscuro que no cabe analizar aquí, la fecha de nuestro texto castellano, considerado como versión de un texto latino, debería aplazarse al último cuarto del siglo XIV. Acercaríamos así la fecha de composición a la fecha de escritura, con un margen de algunos años de diferencia. Es decir, nuestro fragmento se copiaría en el último cuarto del siglo XIV, muy poco después de la aparición de un Raziel latino - y quizá castellano_ y motivado por la novedad de este.

En cuanto a su autor, tampoco disponemos de datos claros. La identificación de Johannes clericus con Juan de Aspa es socorrida, pero no convincente, ya que se basa en la repetición de un nombre demasiado frecuente en los siglos XIIIXIV. Sabida la dificultad de localizar un nombre de autor en este tipo de textos mágicos, podríamos conformarnos con un acercamiento a la figura del copista de nuestro códice toledano y recordar las palabras de Pérez López (2007: 131): el libro estaría formado por "....apuntes de un escolar o copias para su uso sacadas por un eclesiástico de la catedral, también relacionado con el mismo mundo escolar". Parece copia de un escolar, aceptando que la letra de folios como el 78 o 91 podría obedecer a intervenciones puntuales de compañeros o superiores de ese copista estudiante. 


\section{RELACIÓN DE LAS OBRAS MÁGICAS TOLEDANAS CON EL RAZIEL ALFONSÍ EN} SIETE LIBROS ${ }^{2}$

De los cuatro testimonios latinos que transmitirían la versión original de nuestros fragmentos castellanos, tres son accesibles a través de copias digitales. Seguimos aquí la de R: Reg. Lat. 1300, Biblioteca Apostolica Vaticana, Città del Vaticano, ff.117-119 y 129-130, comparándolo con los textos incompletos M: Clm 51, Bayerische Staatsbibliothek, München, ff.115r-115v y 117r, y con L: ms. Plut. 44 cod. 33, Biblioteca Medicea Laurenziana, Firenze, ff.16v-17v y 25 r. Recordemos que estos dos últimos transmiten íntegras, en latín, nuestras obras toledanas. También consultamos la reproducción, de baja calidad, del ms. Barb. Lat. 3859, Biblioteca Apostolica Vaticana, Città del Vaticano, que reproduce una versión occitana, incluida en el Libre de puritats, inédito hasta hoy.

La primera impresión que obtenemos de un cotejo entre el texto latino y el castellano es que nos encontramos ante una versión literal del modelo con algunos matices:

- La grafía de la palabra hoja es muy variable: foyas, ffoyas, fuyas, fuyllas, fuylla y traduce tanto lamina como folia. El texto occitano escibe siempre fuellyas.

- Un término dialectal aragonés u occitano: lur<illorum traduciría el determinante latino posesivo sua.

- Podría considerarse también aragonesismo el ensordecimiento de oclusivas finales, como en suc y lit, esta última, documentada en la literatura alfonsí.

- Encontramos la grafía -nh- en danho. Esto puede obedecer, como la vacilación de las variantes de folia, a una inestable transcripción de sonidos vernáculos, propia de una época temprana del romance.

- La palabra fulán/fulana, de origen árabe, traduce talis hominis/talis femine y ya aparece en escritos alfonsíes.

Destacan varias sustancias de origen vegetal en nuestras fórmulas:

- Los términos mastry, azaffrán, almiz, adecuados para influir sobre Venus, se corresponden con mastice et croco et almizc, sin que ninguno de los tres pueda reconocerse claramente en el ms. M ni en L con esos nombres.

2 Agradezco las valiosas observaciones de Pedro Sánchez-Prieto Borja en la elaboración de este apartado. 
- La corona de rey, que es ros marino responde a la etimología del actual 'romero' y traduce corona regis; hoc est, ros marinus. El ms. M presenta aquí una forma claramente árabe: adikalmalit para esta misma planta.

Los metales son importantes y reconocemos:

- El aranbre amar[illo] traduce eris crocei y se identifica con el cobre o el bronce. En las dos imágenes se recuerda que todo debe escribirse en hojas — fullas - de metal, dentro de una corriente semiculta astronómica.

- Doradas traduce aurate; y de plata, argentea.

El elemento astronómico está presente pese a su vaguedad:

- Los ángeles de la segunda altura son, en una lectura poco clara, guidadores o guardadores de los signos. Los textos latinos leen conservatores signorum en R y gubernatores en M y L.

El repertorio de ángeles o demonios presenta nombres difícilmente legibles e irreconocibles en las versiones latinas y en el fragmento castellano.

Resulta complicado estudiar nuestras obras o ymágenes a partir de un testimonio tan breve y confuso como el manuscrito toledano. Su caligrafía y presentación distan mucho de las que encontramos en códices alfonsíes.

Puede desconcertar leer en el texto vaticano R:

Et inveni in alio libro quod debebant scribi cum suco ipsorum, sed ego credo quod deberet dicere quod scriberentur tria in quolibet folio. Et inveni in uno de exemplaribus quod duo nomina debebant scribi in parte exteriori folii et unum in parte interiori [f.118r/229].

Aunque el fragmento toledano lo presenta confusamente: "fal[l]é en otro [lu]gar", subrayaremos que los textos de $\mathrm{M}$ o L no muestran nada parecido. El hecho de que no aparezca en castellano la sección desde "sed ego credo..." sugiere que el vernáculo sigue una tradición intermedia entre las copias $\mathrm{M}$ y $\mathrm{L}$, por una parte, y R, por otra, ya que este último tuvo dudas que el toledano no planteó de esa manera.

Otro escollo surge de que nuestras dos obras toledanas no sean consecutivas en el texto latino. ¿Estamos ante la copia de fragmentos sueltos o estos proceden de un Libro de Raziel completo? Para plantear la objeción, deberíamos recordar el carácter de nuestro códice toledano. Si se trata de un libro de apuntes académicos, podríamos reconocer en nuestra obra los intereses de un estudiante medieval: ganar amigos, amores de mujeres y salir ileso en sus pendencias. En este sentido, el copista se conformaría con dos o tres fórmulas prácticas y nos encontraríamos lejos del fragmento de una copia completa del 
Raziel en castellano. A favor de la segunda opción, recordamos el comentario de una de las transcripciones dieciochescas del Virgilio Hispano: "No tienen principio ni fin, y por esto sospecho que fué tratado completo" (ms. J-II-9, Real Biblioteca del Monasterio de San Lorenzo, El Escorial, f.5r). Poco convincente parece esta opinión de un erudito ilustrado; menos aún, al ver que en el f.2v del códice de Toledo se copia un tratado gramatical acéfalo con la misma letra que nuestro fragmento. Nos inclinamos a pensar que se trataba de obras sueltas sin continuidad.

Resulta útil en este punto la descripción (Giralt, 2014: 222-224) de una versión occitana incompleta del Libro de Raziel, inserta en la primera parte del Libre de puritats, copiada en el ms. Barb. Lat. 3589, BAV, hacia 1430. Considerando la primera de nuestras obras, se observan desviaciones respecto al texto de $\mathrm{R}$ y al fragmento castellano en algunas aclaraciones. Que el toledano resulte traducción literal del latín, — véase el apéndice I- no excluye que nuestras dos obras castellanas se relacionen con otras versiones occitanas hoy desconocidas, como indican ciertos rasgos del fragmento toledano.

Con todo, y en conclusión, la hipótesis más discreta parece la más aconsejable: nuestro fragmento toledano copiaría obras mágicas aisladas, pero estas obras no son incompatibles con la existencia de un Libro de Raziel castellano.

\section{CRITERIOS DE EDICIÓN}

Publicamos a continuación cuatro apéndices con los siguientes criterios de edición:

- En general, se han resuelto las abreviaturas de los textos originales. No se indica cuando estas resultan absolutamente claras, pero se marcan en cursiva si cabe alguna duda sobre su sentido.

- Las lecturas del texto castellano que se han deducido a partir de su original latino, se recuperan entre corchetes, para indicar letras o caracteres que no se encuentran en el manuscrito toledano, a causa del mal estado de conservación.

- Las letras $<\mathrm{u}>$ o $<\mathrm{i}>$ se transcriben como $<\mathrm{v}>0<\mathrm{j}>$ si tienen valor consonántico, o como $<\mathrm{i}>\mathrm{y}<\mathrm{u}>$ si es vocálico.

- Transcribimos el número $\Lambda$ por 7.

- La acentuación del texto castellano sigue las normas actuales. Busca facilitar su lectura, así como la puntuación en todos los textos.

- En el texto castellano, se reproduce la disposición de líneas que muestra hoy su original, cuyo folio 1 se encuentra rasgado y con varias líneas 
perdidas. Se indica con puntos suspensivos el momento en que se interrumpe la lectura de cada línea por su estado de conservación.

- La función de esta edición es facilitar la lectura del texto romance sobre el apéndice 4. Las lecturas dudosas más relevantes o las correcciones del editor se advierten en notas a este tercer apéndice.

- Se separan y numeran las dos obras toledanas según los ms. latinos, llamando 0 al final fragmentario de una obra anterior a la 1.

\section{APÉNDICES}

En el primer apéndice se coteja el texto castellano con el ms. Reg. Lat. 1300, Biblioteca Apostolica Vaticana, Città del Vaticano. Este se edita por la copia digital de su biblioteca. En este códice vemos una doble foliación: un sistema de foliación — que señalamos con recto y vuelto - junto con una numeración de páginas consecutivas. Reflejamos ambas en la transcripción.

El apéndice 2 pretende ejemplificar, sobre la segunda de nuestras obras, cómo resulta heredera de una tradición que se remonta al Sefer ha-Razim. Se presenta el Cyfra Rasiel (sic) del ms. 3666, Bibliothèque Nationale de France, Paris, y el texto del Cod. mag. 40, Universitätsbibliothek, Leipzig, junto con la traducción inglesa del Sefer ha-Razim (Morgan, 1983) para dar idea de las afinidades entre distintas versiones.

El apéndice 3 es la edición anotada del fragmento castellano.

El cuarto apéndice reproduce de manera facsimilar las dos obras toledanas ${ }^{3}$.

3 Agradecemos la amabilidad de los bibliotecarios y del fotógrafo de la Catedral de Toledo, que han autorizado la reproducción del apéndice 4 sobre un fichero en formato .jpg. 


\section{APÉNDICE 1}

Ms.Reg.Lat.1300

De officiis angelorum

Isti sunt angeli qui sunt in secunda [f.218] altitudine et sunt pleni vigore et potestate. Et sunt parati in beniuolentia et pace et in omni bona concordia ad ponendum societatem inter homines et ad mittendum inter eos amicitiam et concordiam et pacem. Et ad coniungendum fortunas hominibus quia ipsi sunt conservatores signorum et stellarum quoniam descendunt de sua potestate et vadunt inferius.

[Tit.] Ad ponendum benivolentiam, concordiam et amorem inter reges vel alios homines quos volueris.

$\mathrm{Si}$ volueris mittere amicitiam inter inimicos mortales aut facere pacem inter reges vel inter alios homines, aut si volueris coiungere virum mulieri ut invicem nubant, licet non sibi pertineant, accipe duas laminas eris crocei. Et si fuerint de alio metallo, sint de aurate. Et scribe in eis nomina istorum angelorum qui sunt in secunda altitudine ex utraque parte laminarum et nomina illorum inter quos volueris ponere concordiam et sit incaustum cum
Ms.94-22 Bib. Cap. Toledo

[f.1v]

[Obra 0.-]

...que está... ...on apartados en la... ...pora conpagar los honbres... ...amiztança e avinença e paz e per a... es porque ellos son guidadores de los signos ...dotada de lur poder en esta guissa.

[Obra 1.-]

Si quieres meter... ...entre enemigos que son mortales o por paz fer, entre reys o entre hotros honbres o si quisieres aplegar varón con muger por cassar... ...ano maguer que non le perteñecesse, toma dos ffoyas d'aranbre amar[illo]... ...e ssi serán de otra cossa sean doradas

e escrive sobre ellas nonbre... ...estos ángeles que son en la altura secunda d'ambas partes delas foyas e... ...e nonbres d'aquellos [delos] quales quesieres meter lo avinimento e trae......e ssea la tinta con que los escrivieres 
quo hec scribes de mastice et croco et almizc saltem quod/-ia habeat odorem istorum. Et sit ibi modicum de nuic alazerach et de herba que dicitur corona regis; hoc est, ros marinus. Et combures eas et facies de ipsis pulveres et liquefacies istos pulveres cum aqua rosata et cum isto incausto scribes nomina in laminis. Et dices sic: "peto a vobis, o angeli sancti et benedicti, recommendati ad faciendum omne bonum, qui habetis potestatem super signa hominum per que $\mathrm{d} u$ cuntur creatore mundi quod vos mittatis pacem et benivolentiam in similes et magnum amorem inter talem. Et filium talis mulieris nomina et inter tales. Et amoveatur omnem inimicitiam et malivolentia de cordibus ipsorum et de suis voluntatibus et nunquam recordentur de ipsis [f.219/113r] et obliviscantur de eis sicut cor vivi obliviscitur de mortuo". Et si fuerint ad faciendum matrimonium dices sic: "Coniuro vos per nomen illius domini cui estis recommendati et in eius recommendatione et servitio ambulatis et mitto in vestra potestate sua signa que vos coniugatis signum talis hominis, filii talis mulieris, signo talis femine, filie talis. Et mittatis concordiam inter eos et magnam amicitiam et fortem inter signa superius et huc in suis cordibus. Et detis illi homini gratiam et de mastry azaffrán almiz... ...te sequiere la holor d'ella e aya hy un poco de nuez alazara e... ...e herba que dizen corona de rey, que es ros marino e cremar lo al.......aze dello

polvo e desfarás el polvo con agua rossada e con esta... ...scryvirás los nonbres en las fuyas e dirás: "demando yo de vos... ...gloria sodes e bendicchos los comendados sobre todo bien fazer e avedes... [po]der sobre los signos de los ombres, por que guían los criadores del mundo...

...vos metades paz e benquerencia e amor grant entre ...nta e de... ...[s]aquedes toda enemistade e toda $[$ roto $]$ e sus... ...os voluntades e [n] unqua les mienbre e oblidasse te lo... ...1 mares del corraçón del vyvo".

E ssi fuera por cassa[f.2r] mento, dirás assí: "Conjuro vos por el nonbre ...que ... senyor... comen... ...ades sodes e en cuyo comendamento e servicio $\mathrm{d}[$ roto $]$ es ye...

en poder sus signos que vos aplegued[e]s el signo de fulana al signo de fulana, figa de fullana e metades avinimiento... e amistança grant e fuert entre los signos susso e acá en sus co...e dedes dél por gracia e bien fer amistat en sus oios e metades 
beneficium et amicitiam in oculis illius mulieris. Et mittatis eum intus in voluntate eius et non detis potestatem isti mulieri coeundi alteri mulieri injusti. Et non faciat ipsa aliquid sine ipso". Et prohice unam de predictis laminis in aqua unde isti bibunt. Et facias aliam ignem in domo tua et mittas eam in ipso ut conburatur et facias istud in 29 diebus mensis quo compleatur tota lunatio.

De nominibus angelorum tertia alt...

f.229/118r] De opere ad custodiendum te a ferro et ab omnibus modis armorum rubrica

$\mathrm{Si}$ volueris te custodire a sagitta vel ense vel omni modo armorum et ab omni ferro quando fueris in prelio, accipe septem folia de arbore iuniperi. Et scribe in eis nomina angelorum none altitudinis; hoc est, duo nomina in quolibet folio. Et inveni in alio libro quod debebant scribi cum suco ipsorum, sed ego credo quod deberet dicere quod scriberentur tria in quolibet folio. Et inveni in uno de exemplaribus quod duo nomina debebant scribi in parte exteriori folii et unum in parte interiori. dientro en su voluntate e non dedes poder a ella para sseer seguro ha... ...a el mundo ferás ad él. E non ffará cossa ella sines éll". E echa la... ma... foyas en el agua do [roto] ffaes ffogo en tu ca...

quemar e fázelo 29 días del mes que se cunple tota la...[lun]ación.

Estos son los nombres de los ángeles que están en la altura novena

[Obra 2.-]

Si quieres guardarte tú o quien quisieres d...

o d'espada o d[e to]das maneras d'armas e de todo fier[r]o con fueres re... ...at 7 fuylas de árbol de ginebre e escrive en ellas e falé en otro... ...gar que con lo suc dellas los nonbres de los ángeles de la altura novena... [d] os nonbres en cada fuylla 
Et pone illa folia in oleo rosato. Et in die qua debueris exire ad prelium, unge corpus tuum de illo oleo et arma [f.230/118v] tua. Et scribe omnia ista nomina in una lamina argentea et insere eam in alia lamina erea que sit quasi cartula plicata et ligata super cor tuum. Et folia iuniperi sint secundum numerum nominum duo et duo in quolibet et unum in uno et extraas ipsa de oleo. Et include ipsa in corio rubeo et porta tecum ad prelium. Et nulla plaga nec dampnum nec aliquod signum malum erit in corpore tuo nec in te. Et poteris intrare in prelium quodcumque volueris et facere illa que volueris et alii non habebunt potestatem super te.

De nominibus angelorum decime alt...
E échalas en olio rossado e el día que avieres

ssalir a la lit, unta todo tu cuerpo del olio e las armas e escrive todos ...s nonbres sobre huna fuyla de plata e encartónala en aranbre com...

[ca]rtilla plegada e ligada sobre tu coraçón. E las fuyllas del ginebre cuento (delos) delos nonbres dos en cada huna, e huna huno; e sácalas ...no e enciérrales en cuero vermego e lévalas contigo a la lit e ning[una] erida nin nenguno danho nin nenguna se[n]jal mala non avrá en tu c[uerp] o ni en ti. E entrarás en la lit por honte quesieres e farás que quisier... hotros non avrán poder sobre ti. Estos son los nombres de los ángeles... 
APÉNDICE 2

[FROM THE SECOND FIRMAMENT]

If you wish that a man going forth to war be protected from arrow, sword, or any blow, take seven leaves of a bay tree and write these names on them, two on each and every one of them, and put them in spikenard oil, and on the day he goes forth to war, let him smear (the oil) upon his flesh and upon his sword and his bow and arrows. Again write (the names of the angels) on a silver lamella, put them in a bronze tubular case, and let him tie it over his heart, then no blow will touch him.

(Sepher ha-Razim, p.55)
(Cod. Mag. 40, Universitätsbibliothek Leipzig, f.26r/p.47)

$\mathrm{Si}$ vis aliquem preservare ne sagitta, glaudium nec aliud genus armorum, sive sit in proelio vel in itinere, noceat, accipe 7 folia de arbore juniperi, 1. pyri et scribe in ea nomina angelorum 9 altutidinis et quidem bis in quolibet folio et tandem in oleo rosaceum folia pone. Tunc illa die in qua in proelium te commitis, unge totum corpus tuum illo oleo et armas et scribe nomina in folium argenti et involve charta duplicata [in linteo rubeo cum foliis tribus iuniperi] et in pectore nudo gere.

\section{Liber Razielis}

$\mathrm{Si}$ vis custodire vel quitare aliquem a sagitta vel ab ense vel ab omne genere armorum vel ab omne ferro quod fuerit ibi aut in bello r[ecipe] septem folia de arbore iuniperis*. Et scribe in illa nomina angelorum altitudinis none et scribe duo nomina in quolibet folio et proice in oleo rosatus et in die quando oportebit te ire ad bellum, unge te cum oleo dicto totum corpus tuum et tua arma et scribas supradicta nomina angelorum super duo folia argenti et incassabis eas in ramo [ad modum carte plicata et liga illud breve] super cor tuum. Et folia sint in uno nomine duo in quolibet et unum in uno. Et extrahe ex oleo et incassabis in corio rubeo et porta tecum in bello et non habebis aliquam percussionem nec aliquod signum malum in tuo corpore et intrabis in bellum quandocumque volueris et facies quicquid volueris et alii non habebunt posse super te.

*[marg: vel folia lauri]

(Ms.3666 BNF, f.31r) 
APÉNDICE 3

DOS OBRAS MÁGICAS TOLEDANAS DEL LIBRO DE RAZIEL ALFONSÍ

$$
\text { 0.-...que está... }
$$
...on apartados en la... ...pora conpagar los honbres... ...amiztança e avinença e paz e per a... ...es porque ellos son guidadores de los signos ...dotada de lur poder en esta guissa. 1.-Si quieres meter...

...entre enemigos que son mortales o por paz fer, entre reys [o ent]re hotros honbres o si quisieres aplogar barón con muger por cassar... ....ano maguer que non le perteñecesse, toma dos ffoyas d'aranbre amar[illo]... ...e ssi foran de otra cossa sean doradas; e escrive sobre ellas nonbre... ...estos ángeles que son en la altura secunda d'ambas partes delas foyas e... ...e otras d'aquellos [delos] quales quesieres meter lo avinimento e tray... ...e ssea la tinta con que los escrivieres de mastry azaffrán almiz... ...te se quiere la holor d'ella e aya hy un poco de nuez alazara e... ...e herba que dizen corona de rey, pero es ros marino e cremar lo al... ...aze dello polvo e desfarás el polvo con agua rossada e con esta... ...scryvirás los nonbres en las fuyas e dirás: “demando yo de vos... ...gloria sodes e bendicchos los comendados sobre todo bien fazer e avredes... par sobre los signos de los ombres, por que guían los criadores del mundo... ...vos metades paz e benquerencia e amor grant entre ...nta e...de... .... [s]aquedes toda enemistade e toda [roto] e sus... ...os voluntades e nunqua les mienbre e oblidasse te lo... ...1 mares del corraçón del vyvo". E ssi fuera por cassa-

[f.2r] mento, dirás assí: "Conjuro vos por el nonbre ...que ... senyor... comen... 
...ades sodes e en cuyo comendamento e servicio d[roto $]$ es ye... en poder sus signos que vos aplegued[e]s el signo de fulano al signo de fulana, figa de fullana e metades avinimiento... e amistança grant e fuert entre los signos susso e acá en sus co... e dades dél por gracia e bien fer amistat en sus oios e metades dientro en su voluntate e non dedes poder a ella para sseer perjuro ha... ...a él mundo ferás ad él. E non ffará cossa ella sines éll. E echa la... ma... foyas en el agua do [roto] ffaes ffogo en tu ca... quemar e fázelo 29 días del mes que se cunple tota la...[lun]ación.

Estos son nonbres de los ángeles que están en la altura novena: Guedi, Oie... ...iel, Tarquasemel, Nasciel, Azra, Bama, Oliel, Toqoel, Chaquiel, Ajsbial Byel, Catay, Asalpiel, Catyel, Sacriel, Tarsomel, Naqriama, Sacq... Carbaciel, Partael, Patyel.

2.-Si quieres guardarte tú o quien quisieres d...

o d'espada o d[e to]das maneras d'armas e de todo fier[r]o con fueres re... ....at [toma] 7 fuylas de árbol de ginebre e escrive en ellas e fal[1]é en otro... [lo]gar que con lo suc dellas los nonbres de los ángeles de la altura novena [d] os nonbres en cada fuylla e échalas en olio rossado e el día que avieres ssalir a la lit, unta todo tu cuerpo del olio e las armas, e escrive todos ...s nonbres sobre huna fuyla de plata e encartónala en aranbre com... [ca]rtilla plegada e ligada sobre tu coraçón. E las fuyllas del ginebre cuento (delos) delos nonbres dos en cada huna; e huna, huno; e sácalas ...no e enciérrales en cuero vermego e lévalas contigo a la lit e ning[una] erida nin nenguno danho nin nenguna senyal mala non avrá en tu c[uerp] o ni en ti e entrarás en la lit por honte quesieres e farás que quesier... hotros non avrán poder sobre ti. Estos son nonbres de los ángeles de la [a]ltura: Gigrel, Cuiva, Carcael, Patuquiel, Necriel, Del, Yoch, Hyhehu, Betas ...acfun, [roto]tos, Chebaet, Amar[e]l, Lael, Maxibach, Cona, Dicias, ... Actiel, Q[roto], Bajas, Ho, Batas, Humanuez, A...ctu

Joaban.
Cax 17-4
Cax 21-4 


\section{NOTAS}

1.3: la contracción pora data de una época próxima al siglo XIII.

1.5: podría leerse guardadores, pues el modelo latino lee conservatores, que sugiere esta lectura. Los fragmentos de Munich y Florencia proponen gubernatores. Sin embargo, en la 1.20 leemos guían y no guidan. Guidar, quizá de origen germánico, podría ser un aragonesismo.

1.8: ganar la benevolencia de los reyes es un deseo que puede encontrarse desde las imagines de Thabit Ibn Qurra.

1.16: ros marino, como se dijo más arriba, se relaciona, en el libro II de Raziel, con el romero.

1.24: la lectura vyvo viene sugerida por el modelo latino -cor vivi- y por el sentido de la frase. El manuscrito toledano ofrece algo ilegible, como equd o agud.

1.31: Se duda entre seguro -mantengo esta lectura en el primer apéndice- y perjuro. 1.35-38: como se señaló más arriba, los nombres de los ángeles son ilegibles y no se parecen a los de ningún otro manuscrito latino o vernáculo.

1.41: el 7 aparece escrito como $\Lambda$ en el ms. toledano.

1.50: quizá qualquisiere.

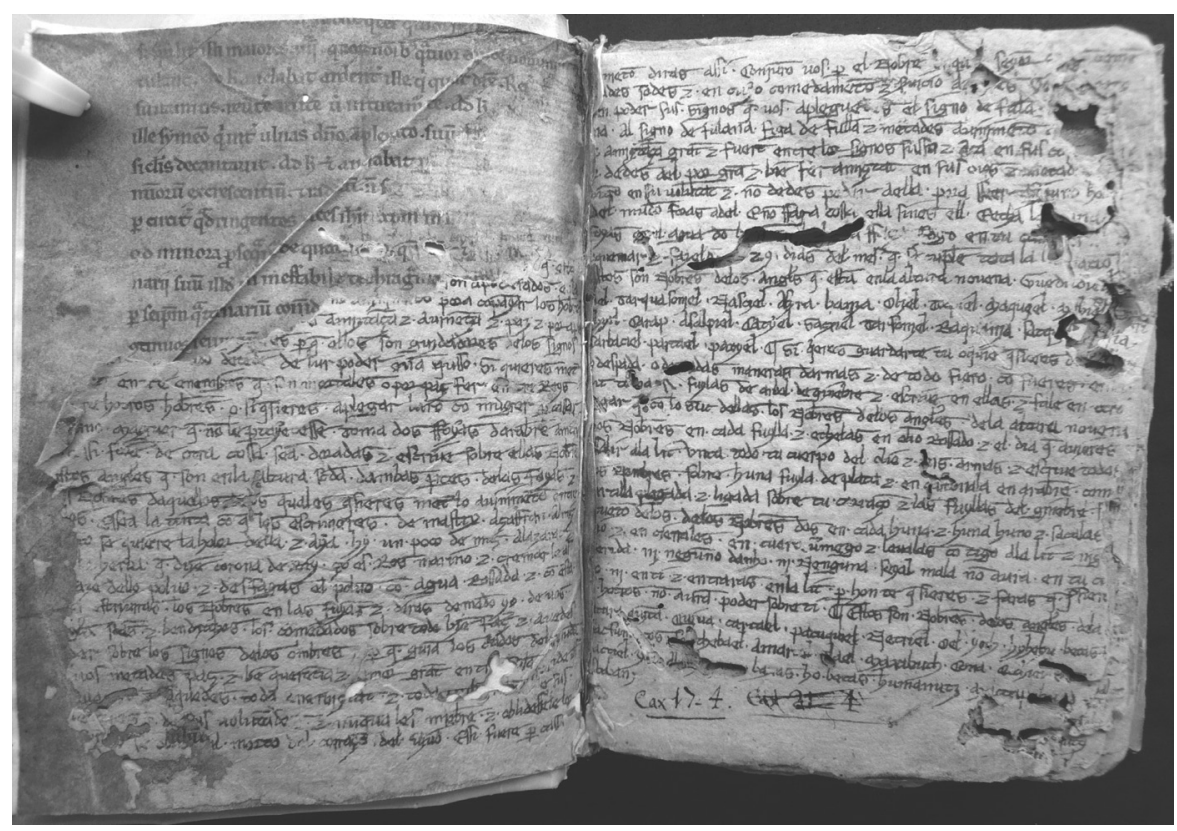

APÉNDICE 4 


\section{MANUSCRITOS}

Liber Razielis, [R] ms. Reg. Lat. 1300, Biblioteca Apostolica Vaticana, Città del Vaticano (consultado en https://digi.vatlib.it/view/MSS_Reg.lat.1300).

Liber Razielis, $[\mathrm{H}]$ ms. 14 B 36, Universitäts- und Landesbibliothek, Halle (no consultado).

Liber Razielis (libs VI-VII) [M] ms. Clm 51, Bayerische Staatsbibliothek, München, ff.111r-123v (consultado en https://www.digitale-sammlungen.de/index.html?c=suchen\&ab=\&kl=\&l=de).

Raziel Liber Secretorum, [L] ms. Plut. 44 cod. 33, Biblioteca Medicea Laurenziana, Firenze (consultado en http://www.internetculturale.it/it/950/codici-per-provenienza-e-segnatura).

Liber Razielis, ms. 3666, Bibliothèque Nationale de France, Paris (consultado en https://gallica.bnf. fr/ark:/12148/btv1b10038528n/f3.item).

Liber Razielis, Cod. mag. 40, Universitätsbibliothek, Leipzig, (consultado en https://histbest.ub.unileipzig.de/receive/UBLHistBestCBU_cbu_00000063).

"Ex Libro Razielis", ms. lat. oct. 231, Universitätsbibliothek Johann Christian Senckenberg, Frankfurt, ff.96r-97v (consultado en http://sammlungen.ub.uni-frankfurt.de/5088494).

Diversas obras, ms. 94-22 Bib. Cap. Toledo.

Libre de puritat, ms. Barb. Lat. 3589, Biblioteca Apostolica Vaticana, Città del Vaticano (consultado en https://digi.vatlib.it/view/MSS_Barb.lat.3589).

\section{BIBLIOGRAFÍA}

D'Agostino, Alfonso (1979): Il "Libro sulla magia del segni" ed altri studi di filologia spagnola, Brescia, Paideia, pp. 21-64.

D'Agostino, Alfonso (ed.) (1992): Astromagia, Napoli, Liguore editore.

Barrientos, Lope (1994): Tractado de la divinança, Cuenca, ed. Paloma Cuenca Muñoz.

Faulhaber, Charles (2016): PhiloBiblon, BETA texid 4996; manid 4874.

Fernández Fernández, Laura (2013): Arte y ciencia en el scriptorium de Alfonso X el Sabio, Sevi1la/Puerto de Santa María, Universidad de Sevilla/Cátedra Alfonso X el Sabio.

García Avilés, Alejandro (1997): “Alfonso X y el Liber Razielis: imágenes de la magia astral judía en el scriptoriumalfonsî”, Bulletin of Hispanic Studies, 74, pp. 21-39, <https://doi.org/10.1080 /000749097760143517>.

Gehr, Damaris (2012): "La fittizia associazione del Liber Razielis in sette libri ad Alfonso X il saggio e una nuova determinazione delle fasi redazionali del trattato, della loro datazione e dell' identità dei compilatori coinvolti”, Viator 43, Multilingual, pp. 181-210.

Giralt, Sebastià (2014): "The Manuscript of a Medieval Necromancer: Magic in Occitan and Latin in Ms. VATICANO, BAV, BARB. LAT. 3859", Revue d'histoire des textes, 9, pp. 221-272.

Laat, Sanne de (2018): Liber Salomonis. A Parallel Edition with Introduction and Appendices, Radboud Universiteit Nijmegen (ed. electrónica).

Martínez, H. Salvador (ed.) (2016): Filosofía de Virgilio de Córdoba. Aristotélico-averroísta del siglo XIII, León, Universidad de León, pp. 95-100.

Martínez de Carnero, Fernando (2002): "De Raziel a la teosofía. Magia y literatura en España", Artifara, n. 1, (luglio - dicembre 2002), sezione Monographica, <http://www.artifara. com/rivista1/testi /Raziel.asp>.

Millás Vallicrosa, José María (1942): Las traducciones orientales en los manuscritos de la Biblioteca Catedral de Toledo, Madrid, CSIC.

Morgan, Michael A. (1983): Sepher ha-Razim. The Book of the mysteries, California, Scholars Press Chico.

Pérez López, José Luis (2007): Temas del Libro de buen amor, Toledo, d. b. eds. 
Secret, François (1969): "Sur quelques traductions du SêferRaż̃lel", Revue des études juives, 128, pp. 223-245.

Thorndike, Lynn (1947): "Traditional Medieval Tracts concerning engraved astrological Images", en Mélanges Auguste Pelzer, Louvain, Bibliothèque de l'université-Éditions de l'Institute supérieur de Philosophie, pp. 217-274.

Vaccaro, Anna Maria (1959): Kancaf el indio sulle ventiotto mansioni lunari, separata de Annali della Facoltà di Magistero dell’Università di Palermo.

Fecha de recepción: 28 de agosto de 2019

Fecha de aceptación: 24 de febrero de 2020 